Nevșehir Bilim ve Teknoloji Dergisi TARGíd Özel Sayı 272-279 2016

DOI: 10.17100/nevbiltek.211007

URL: http://dx.doi.org/10.17100/nevbiltek.211007

\title{
Şeker Pancarı Tarımında Penetrasyon Direncinin Belirlenmesi
}

\author{
Hamza Negiş*, Cevdet Şeker, İlknur Gümüş, Hasan Hüseyin Özaytekin, Emel Atmaca, Ümmühan
}

Karaca

Selçuk Üniversitesi Ziraat Fakültesi, Toprak Bilimi ve Bitki Besleme Bölümü, Kampüs/KONYA

Öz

Şeker pancarı tarımı yapılan arazilerde yoğun trafiğe bağlı olarak toprak penetrasyon direnci ve hacim ağırlığı artarken kök gelişimi ve ürün verimi azalmaktadır. Bu araştırmada Konya ili Çumra ilçesi Çumra serisinde şeker pancarı tarımı yapılan alanlarda karşılaşılan toprak sıkışması probleminin penetrasyon ölçümleriyle belirlenmesi, penetrasyon direnci değerlerine etki edebilecek bazı toprak fiziksel özelliklerinin bulunması ve karşılaştırılması amaçlanmışıır.

Bu amaçla Çumra serisini temsil eden 27 farklı araziden penetrasyon ölçümleri yapılmış ve fiziksel analizler için (toprakların kum, kil, silt içeriği, kütle yoğunluğu, agregat stabilitesi, por büyüklüğ̈̈ dağılımı ve nem içerikleri) bozulmuş ve bozulmamış toprak örnekleri alınmıştır.

Çalışmada üst katman penetrasyon direnci $(0-20 \mathrm{~cm})$ ve alt katman penetrasyon direnci $(20-40 \mathrm{~cm})$ arasındaki farkların her bir toprak örneğinde arttığı gözlemlenmiş ve profillerde özellikle pulluk katmanında $(20-40 \mathrm{~cm})$ sıkışmanın varlığı belirlenmiş ve bitki gelişimi için kritik seviye kabul edilen değerden (PD>2 MPa) büyük olduğu gözlemlenmiştir.

Anahtar Kelimeler: hacim ağırlığı, penetrasyon direnci, şeker pancarı, toprak sıkışması

\section{Determination of Penetration Resistance in Sugar Beet Farming}

\begin{abstract}
While soil penetration resistance and bulk density are increasing due to intensive field traffic, root development and product yield are decreasing on lands cultivated with sugar beet. In this study it was purposed that soil compaction problem which is encountered in sugar beet farming areas in Çumra district of Konya city, will determined by penetration measurements. Furthermore, some physical properties that may effect on the penetration resistance value, were evaluated in soil and these properties were compared. In order to this aim, penetration measurements were performed in soils obtained from 27 different areas which represented Çumra series, and disturbed and undisturbed soil samples were taken for physical analysis (sand, clay and loam contents of soils, mass density, aggregate stability, pore size distribution and soil moisture).

In this study, differences between top layer penetration resistance $(0-20 \mathrm{~cm})$ and the lower layer penetration resistance $(20-40 \mathrm{~cm})$ were increased in every soil samples. In profiles, especially in the plow layer $(20-40 \mathrm{~cm})$, the presence of compaction was determined and it was observed that measured penetration values were more than PR $>2$ MPa which was considered critical level for plant growth
\end{abstract}

Keywords: Mass density, penetration resistance, sugar beet, soil compaction

\footnotetext{
*e-mail: hnegis@selcuk.edu.tr
} 
1. Giriş

En önemli doğal kaynaklarımızdan olan toprakların verimli ve sürdürülebilir kullanımı; toprakların özelliklerinin en iyi şekilde belirlenmesi, verimlilik üzerine etkili olan değerlerin ve kısıtlamaların bulunması sürdürülebilirlik bakımından ele alınması ile mümkündür.

Doğal kaynaklar olan toprakların verimli ve sürdürülebilir kullanımı ülkelerin gelişmişlik düzeyleri ile artmaktadır. Ülkemizdeki en önemli doğal kaynaklardan olan topraklarımızın sürdürülebilir kullanımı, ülkemizin tarım potansiyelini arttırmada ve verimde önemli rol oynamaktadır. 2014 yılı istatistiklerine göre ülkemizde 21.351 .000 hektarlık alanda işlemeli tarım yapılmakta olup, bu alanın yaklaşı 16.217 .000 hektarı her yıl ekilirken (\% 76 ) 4.323 .000 hektarlık alan (\% 24) ise her yıl nadasa bırakılmaktadır [1]. Nadasa bırakılmayan alanda toprak işleme, topraklar üzerinde yoğun olarak tarla trafiği oluşturmaktadır. Çumra ovasında şeker pancarı üretimi yapılan arazilerde yapılan araştırmalar sonucunda toprakların verim potansiyelinin altında kullanıldığı gözlemlenmiştir. Çumra ovasında şekerpancarı verimi 2013 yılında dekara 7284 kg'dır [2]. Şeker pancarı üretiminde en önemli husus olan şeker içeriği ise düşük oranlarda kalmaktadır.

Topraklarda meydana gelen fiziksel bozulmalar daha çok toprak işleme, tohum yatağı hazırlama, ekim, bakım ve hasat faaliyetlerine bağlı olarak değişmektedir. Özellikle uygun olmayan şartlarda, uygun olmayan ekipmanlar ile yapılan fazla toprak işleme fiziksel toprak bozulmasının en önemli sebepleridir. Buna ekim nöbeti, amenajman faaliyetlerindeki eksiklik ve yanlışlıkların eklenmesi bozulmanın etkisini daha da artırmaktadır. Toprak strüktürünün bozulması, agregat stabilitesinin azalması, toprak sıkışmasına bağlı olarak, hacim ağırlığının artması, gözenekliliğin azalması, su ve hava geçirgenliğinin düşmesi, yüzeyde kaymak tabakası oluşumu ve penetrasyon direncinin artması fiziksel bozulmanın en önemli göstergeleridir.

Toprak sıkışması; infiltrasyon oranını, yüzey akışını, nitrojen döngüsünü ve kök ve bitki gelişimini etkilediğinden dolayı önemli bir toprak kalite kriteridir. Yoğun tarla trafiğine maruz kalan arazilerde yüksek penetrasyon direnci bitki kök gelişimi ve topraklarda bitki besin elementi alımı azalmaktadır[3].

Toprakların infiltrasyonunu ve yüzey akışını etkileyen yüksek hacim ağırlı̆̆ı, toprak sıkışmasının bir göstergesidir. [4] tarafından yapılan çalışmada 3 aylık otlatma periyodu içerisinde belirli noktalardan hacim ağırlığı ve penetrasyon direnç değerlerini belirlenmiş, bu değerlerin yersel değişkenlik dağılımlarını yapılmıştır. 3 aylık bu periyod içerisinde hacim ağırlığında ortalama olarak zamansal bir değişim olmadığ 1 gözlemlense de yüksek penetrasyon direncinin kök gelişimi için kritik seviyelerde olduğu belirlenmiştir. Toprak sıkışmasının bazı fiziksel özelliklerle değerlendirilmesi amacıyla yapılan çalışmada Büyük Menderes havzasında yaygın iki toprak serisi seçilmiştir. Araştırma bulgularında 40-50 cm'de sıkışmanın olduğu belirlenmiş ve bu derinliklerde hacim ağırlığında artış, makro gözenek miktarında da azalma görülmüştür [5]. Yaptıkları çalışmada kumlu tın tekstür grubuna ait toprağın farklı traktör geçişindeki toprak profilindeki gözenekliliğe ve sıkışmaya etkisi araştırılmıştır. Tarla kapasitesine yakın nem içeriğine sahip topraklarda toprak yüzeyinden 1-2-4 defa geçirilen lastik tekerlekli traktörün geçişi sağlanmıştır. Yapılan işlem sonucunda toprağın hacim ağırlığı ve penetrasyon direnç değerlerinde artışlar meydana gelmiştir [6]. 
$\mathrm{Bu}$ araştırmada Konya ili Çumra ilçesi Çumra serisinde şeker pancarı tarımı yapılan alanlarda karşılaşılan toprak sıkışması probleminin penetrasyon ölçümleriyle belirlenmesi, penetrasyon direnci değerlerine etki edebilecek bazı toprak fiziksel özelliklerinin bulunması ve karşılaştırılması amaçlanmıştır.

\section{Materyal ve Metot}

Araştırmada kullanılan toprak örnekleri Konya ili Çumra ilçesinden alınmıştır. İlçedeki toplam 1.484.440 da işlenen alanın \%70.29'unde tarla arazileri, \%26.69'unda nadas alanları, \%2.29'unde sebze alanları bulunmaktadır. İlçe tarla arazilerinin \%18.30 şeker pancarı üretimi için ayrılmıştır [2]. Yapılan bu çalışmada Çumra ovasında farklı tekstür grubuna ait 27 farklı şeker pancarı tarımı yapılan araziden toprak sıkışmasını belirlemek amacıyla beş tekerrürlü olarak $0-40 \mathrm{~cm}$ derinlikte penetrasyon direnci okumaları yapılmıştır. Arazilerden toprak nemini belirlemek için aynı anda örnekleme yapılmış, çeşitli fiziksel ve kimyasal analizler içinde bozulmuş ve bozulmamış toprak örnekleri alınmıştır.

Araziden alınan toprak örnekleri kurutulup öğ̈̈tüldükten sonra $2 \mathrm{~mm}$ 'lik elekten elenerek hazır hale getirilmiştir. Mekanik analiz Bouyoucos Hidrometre yöntemi [7], organik madde CN LECO cihazı ile Dumas metoduna göre [8], agregat stabilitesi [9], kireç içeriği [10] ve hacim ağırlığı bozulmamış örnek silindirleri ile belirlenmiştir [7]. Toprak sıkışmasının yüzeysel ve toprağın alt katmanlarına yaptığı etkiyi araştırmak için 0-20 ve 20-40 cm olmak üzere penetrasyon direnç ölçümleri Eijkelkamp firması tarafından üretilen penetrologger yardımıyla yapılmıştır. Ölçülen değerler bilgisayar ortamına aktarılıp toprak özellikleri ile karşılaştırmak için düzenlemeler yapılmıştır. Yapılan penetrometre okumaları nem değişime göre standart hale getirmek için aşağıdaki denklem kullanılmıştır [11-17]. İstatistiksel değerlendirmeler Minitab paket programı kullanılarak yapılmışırı[18].

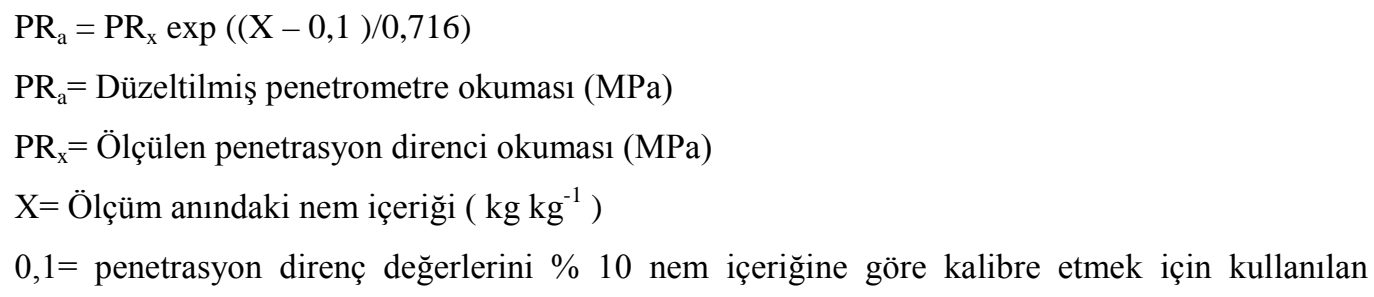
katsay

\section{Bulgular}

Yapılan araştırmalarda Çumra ovasında 27 farklı araziden elde edilen değerler sonucunda şeker pancarı tarımı yapılan arazilerde toprak sıkışması belirlenmiş ve bu topraklarda çeşitli fiziksel ve kimyasal analizler yapılmıştır. Çalışma alanı topraklarının tekstür sınıfları C, SC ve SCL olarak belirlenmiş̧ir (Şekil 1). Topraklar yüksek oranda kireç içermekte (\%15.61), düşük organik madde ihtiva etmekte (\%1.51), agregat stabilitesi yönünden zayıf (\%13.75) ve hacim ağırlıkları ortalama olarak yüksek değerlere sahip olduğu $\left(1.44 \mathrm{~g} / \mathrm{cm}^{3}\right)$ belirlenmiştir. Farklı tekstür gruplarına ait topraklarda hacim ağırlı̆̆ değerleri bitki gelişimi için farklılık göstermektedir. Bu değerler killi topraklarda 1.5-1.6 g/ $/ \mathrm{cm}^{3}$ iken tınlı ve kumlu topraklarda $1.6-1.8 \mathrm{~g} / \mathrm{cm}^{3}$ olduğu vurgulanmıştır [19]. Çalışma alanının 0-40 cm'deki 
penetrasyon direnci değerleri (Şekil 2'de) gösterilmiştir. Yapılan ölçümlerde en düşük penetrasyon direnci 1,15 MPa, en yüksek penetrasyon direnci ise 3,61 MPa olarak tespit edilmiştir.

\section{Tekstür İçeriği}

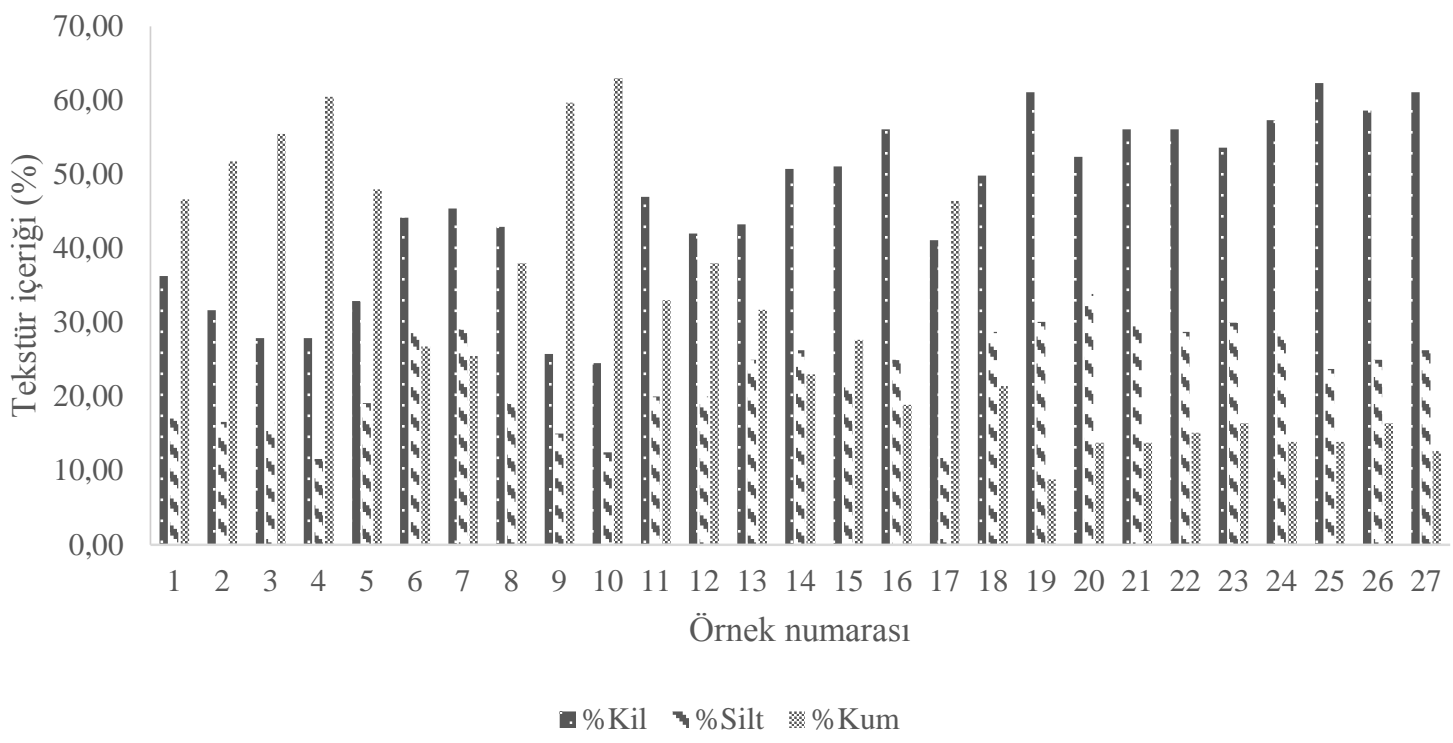

Şekil 1: Çalışma alanı topraklarının tekstür içeriği

\section{Penetrasyon direnci}

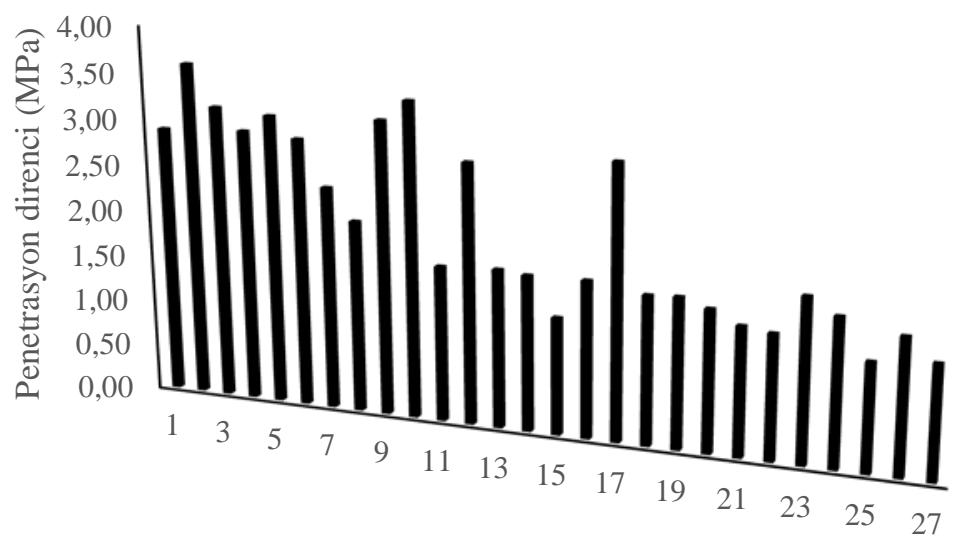

Örnek numaras1

Şekil 2: Çalışma alanı topraklarının penetrasyon direnci değerleri 
Negiş H., Şeker C., Gümüş İ., Özaytekin HH., Atmaca E., Karaca Ü.

Tablo 1. Araştırma Topraklarının Bazı Fiziksel ve Kimyasal Özelliklerinin Ortalama Değerleri ve İstatistiksel Analizleri

\begin{tabular}{|c|c|c|c|c|c|}
\hline Değişkenler & Ortalama & $\mathrm{SS}^{*}$ & $\% \mathrm{CV}^{*}$ & Min & Max \\
\hline Penetrometre 20-40 MPa & 2,21 & 0,91 & 41,49 & 1,11 & 3,75 \\
\hline$\%$ Kil & 45,89 & 11,67 & 25,42 & 24,50 & 62,35 \\
\hline$\%$ Silt & 23,00 & 6,38 & 27,73 & 11,60 & 33,85 \\
\hline$\%$ Kum & 31,12 & 17,17 & 55,18 & 8,80 & 63,00 \\
\hline Organik madde \% & 1,514 & 0,40 & 26,43 & 1,03 & 2,89 \\
\hline Agregat stabilitesi \% & 13,75 & 8,93 & 64,92 & 4,35 & 42,93 \\
\hline
\end{tabular}

*SS: standart sapma; CV: değişim katsayısı

Tablo 2. Araştırma Topraklarının Bazı Fiziksel ve Kimyasal Özelliklerinin Korelasyon Matrisi

\begin{tabular}{|c|c|c|c|c|c|c|c|}
\hline & $\%$ Kil & $\%$ Silt & \% Kum & $\begin{array}{l}\text { Penetrasyon } \\
\text { direnci }\end{array}$ & $\begin{array}{c}\mathrm{Pb} \\
\left(\mathrm{g} \mathrm{cm}^{-3}\right)\end{array}$ & \% Kireç & $\begin{array}{c}\text { Organik } \\
\text { madde (\%) }\end{array}$ \\
\hline \multirow{2}{*}{$\%$ Silt } & 0,787 & & & & & & \\
\hline & 0,000 & & & & & & \\
\hline \% Kum & 0,000 & 0,000 & & & & & \\
\hline \multirow{2}{*}{$\begin{array}{l}\text { Penetrasyon } \\
\text { direnci (MPa) }\end{array}$} & $-0,910$ & $-0,713$ & 0,885 & & & & \\
\hline & 0,000 & 0,000 & 0,000 & & & & \\
\hline $\mathrm{Pb}\left(\mathrm{g} \mathrm{cm}^{-3}\right)$ & 0,001 & 0,025 & 0,001 & 0,012 & & & \\
\hline \multirow{2}{*}{ \% Kireç } & 0,593 & 0,485 & $-0,582$ & $-0,589$ & $-0,357$ & & \\
\hline & 0,001 & 0,010 & 0,001 & 0,001 & 0,068 & & \\
\hline \multirow{3}{*}{$\begin{array}{l}\text { Organik madde } \\
\text { (\%) } \\
\text { Agregat } \\
\text { stabilitesi }\end{array}$} & 0,331 & 0,322 & $-0,346$ & $-0,273$ & 0,493 & 0,182 & \\
\hline & 0,091 & 0,101 & 0,078 & 0,168 & 0,009 & 0,356 & \\
\hline & 0,458 & 0,666 & $-0,559$ & $-0,446$ & $-0,052$ & 0,587 & 0,245 \\
\hline
\end{tabular}

Toprak özelliklerinin toprak sıkışmasının üzerinde etkilerini belirlemek için korelasyon analizi yapılmıştır (Tablo 2.). Buna göre toprakların sıkışması ile kum miktarı arasında yüksek korelasyon katsayısına sahip $(0,885)$ önemli $(\mathrm{P}<0.01)$ pozitif bir ilişki elde edilmiştir. Toprak sıkışması ile kil, silt ve kireç değerleri karşılaştırıldığında sırasıyla korelasyon katsayıları (-0,910, -0,713 ve -0,589) sonuçları bulunmuş ve penetrasyon direnci ile aralarında önemli $(\mathrm{P}<0.01)$ negatif bir ilişki sonucuna ulaşılmıştır. Toprak sıkışması ile agregat stabilitesi arasında $(\mathrm{P}<0.05)$ negatif bir ilişki olduğu tespit edilmiştir. Yapılan çalışmalarda topraklarda üst katman (0 -20 cm)' deki sıkışmaya en etkili olan göstergenin olarak toprak tesktürü olduğu vurgulanmıştır [21].

Toprak sıkışmasını etkileyen en önemli toprak özelliği toprak nem içeriğidir. Toprak tekstürü de toprak sıkışmasında önemli rol oynamaktadır [20]. Yapılan çalışmada toprak sıkışması ile tekstür arasında önemli anlamlı ilişkiler bulunmuştur. Araştırmada (Şekil 3 ve 4' de) toprak sıkışmasının kil ile kum fraksiyonu arasındaki ilişkiler belirlenmiş ve yüksek $\mathrm{R}^{2}(0,78,0,83)$ değerleri elde edilmiştir. 


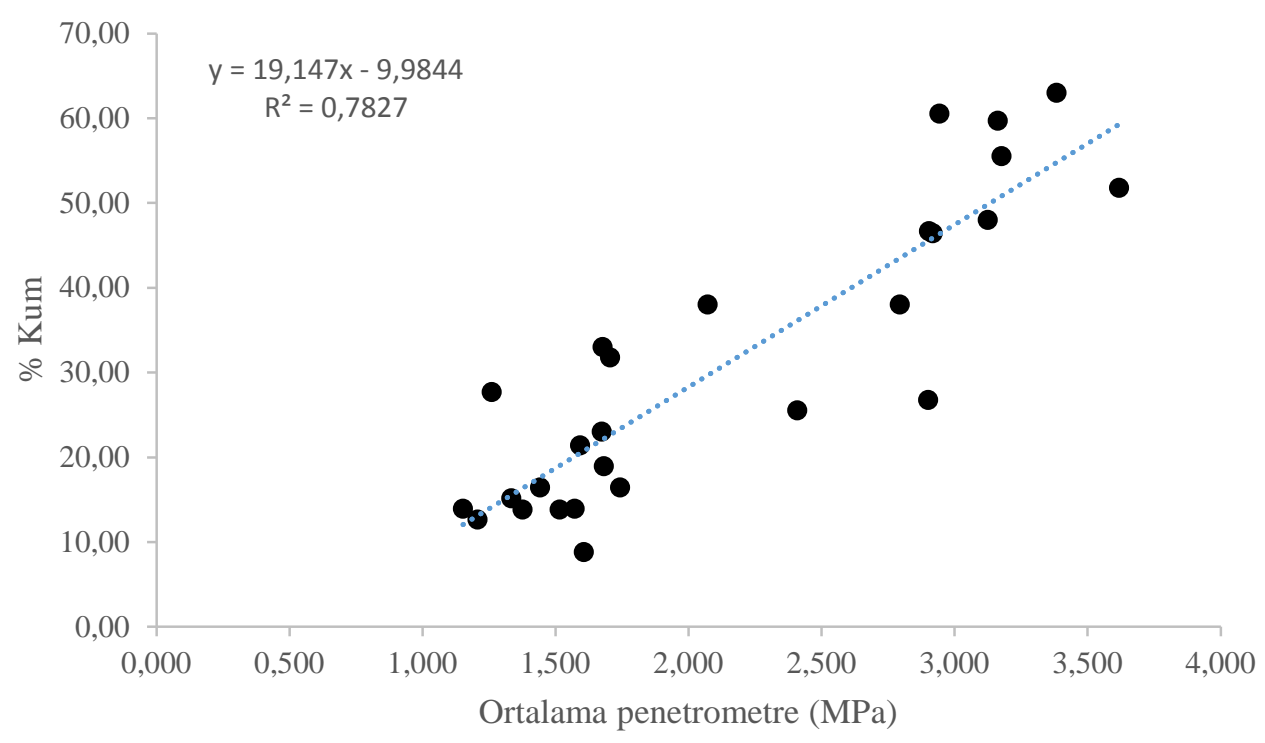

Şekil 3: Ortalama penetrasyon direnci ile \%kum arasındaki ilişsi

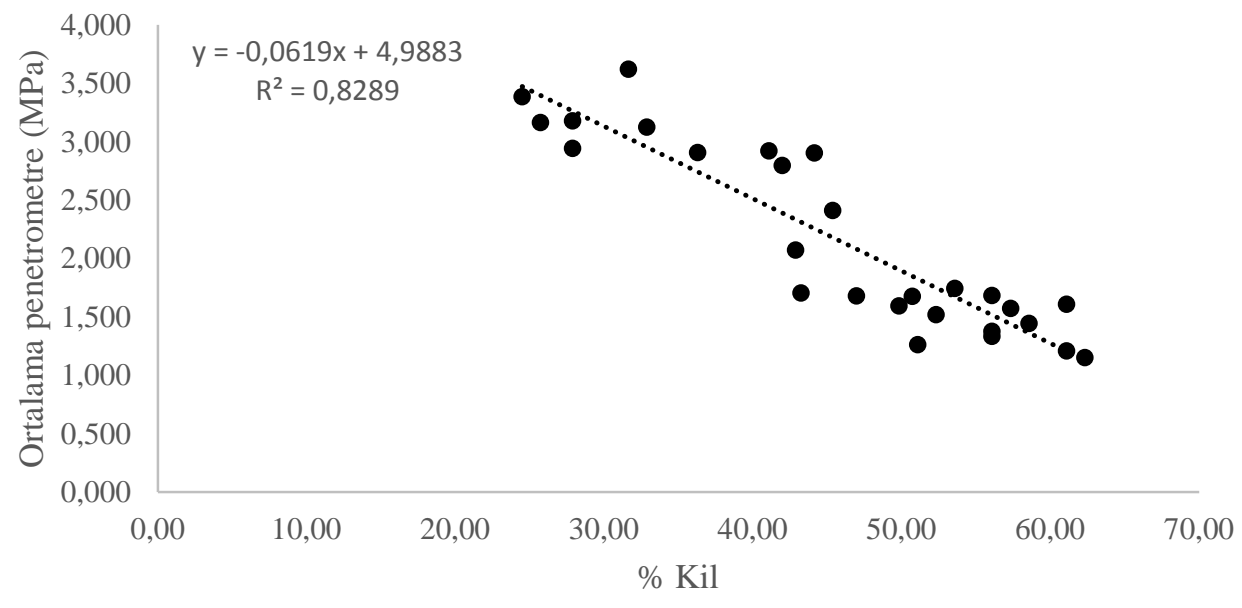

Şekil 4: Ortalama penetrasyon direnci ile \%kil arasındaki ilişki

\section{Tartışma ve Sonuç}

Toprak penetrasyon dirençleri ele alındığında üst katman penetrasyon dirençleri 0.53 ile 2.99 MPa arasında değişirken, alt katman penetrasyon dirençleri 1.11 ile $3.75 \mathrm{MPa}$ arasında değişim göstermiştir. Ortalama penetrasyon direnç değerleri karşılaştırıldığında 1.15 ile 3.61 arasında değişmektedir. Yüksek penetrasyon direnci değerlerine sahip topraklarda bitkinin toprak dışında gelişimi, bitkide kök çatallanması, yağış veya sulama suyunun toprak içindeki hareketinin azalması, infiltrasyon oranının azalıp yüzey akışııın meydana gelmesi sıkışmasının en büyük göstergelerindendir.

Araştırmada toprak sıkışmasına etki eden en önemli toprak özelliklerinin toprakların tekstür içeriği olduğu tespit edilmiştir.

[22] yaptığı araştırmalar sonucunda şeker pancarı tarımında dönemsel tarla trafiği toprak sıkışmasını etkileyen en önemli özelliklerden biridir. Şeker pancarı tarımı yapılan alanlarda 4 farklı 
dönemde (ekim öncesi, ekim sonrası, gelişme dönemi ve hasat sonrası) toprak sıkışmasını belirlemek için yapılan penetrasyon ölçümlerinde, gelişme dönemi ve hasat sonrası dönemlerde ekim öncesi ve ekim sonrası yapılan ölçümlere göre anlamlı farkl1lıklar $(\mathrm{p}<0.01)$ ortaya çıkmış ve bitkinin gelişimi için kritik seviyelerde olduğu belirtilmiştir. Toprak penetrasyon direncinin (>2 MPa) üzerinde olduğu zaman bitki kök gelişimi için kritik seviyeye ulaştığı vurgulanmıştır [23].

Tarım topraklarımızın değişmez özelliklerinden olan tekstür özelliğini farklılaştıramadığımızdan dolayı farklı yöntemlerle topraklarımızdaki sıkışmayı azaltacak uygulamalara yer verilmesi önem arz etmektedir. Tarımsal sistemde toprak sıkışmasına etki eden unsurların başında gelen toprağı uygun olmayan nemde işleme düzeninden uzaklaşmak ve toprakları daha az sıkışmaya yönlendirecek alet ve ekipman kullanmak gibi kısa vadeli alınacak önlemler ve toprak organik madde artırımı gibi ve münavebe uygulaması yapılması gibi uzun vadeli önlemlerin alınması uygun görülmektedir.

\section{Teşekkürler}

Yapılan bu çalışmada kullanılan toprak örneklerine ait bilgi ve rakamsal veriler TÜBİTAKTOVAG tarafindan (1001) desteklenen $112 \mathrm{O} 14$ numaralı (2013) ve "Çumra Ovasında Önemli ve Yaygın Üç Toprak Serisinin Toprak Kalite İndislerinin Belirlenmesi” isimli devam eden çalışmadan alınmıştır.

\section{Kaynaklar}

[1] Anonim, 2014, Türkiye İstatistik Kurumu Genel Müdürlüğü http://www.tuik.gov.tr/Ustmenu.do?metod=temelist

[2] Anonim, 2013, Türkiye İstatistik Kurumu Genel Müdürlüğü http://www.tuik.gov.tr/Ustmenu.do?metod=temelist

[3] Altıkat S., Çelik A., “ Toprak işleme sistemlerinin önemli bazı toprak kalite kriterlerine olan etkileri” Alınteri, 16(B), 33-41, 2009

[4] Aksakal, E.L., Öztaş, T., Özgül, M., "Time-dependent changes in distribution patterns of soil bulk density and penetration resistance in a rangeland under overgrazing” Turk $\boldsymbol{J}$ Agric For., 35;1-10-383, 2011

[6] Şeker, C., Işıldar, A., "Tarla trafiğginin toprak profilindeki gözenekliliğe ve sıkışmaya etkisi” Türk J. Agric. For., 24, 71-77, 2000

[7] Demiralay İ., "Toprak fiziksel analizleri”. Atatürk Üniversitesi Ziraat Fakültesi Yayınlarl, No, 143, Erzurum, 1993

[8] LECO Corporation, “Truspec carbon/nitrogen determinator. Leco Corporation 3000” Lakeview Avenue, St Jeseph, M1 49085-2396, USA, 2003

[9] Kemper, W. D., "Aggregate stability. in : methodsof soil analysis part I (Black, C.A., ed.)” American society of agronomy, inc. madison, wisconsin, 511-519s USA, 1965

[10] Kacar, B., “Toprak Analizleri” Nobel Yayın Dağıttm Tic. Ltd. Şti. ISBN 978-605-395-184-1. 2009

[11] Perumpral, J. V., “Cone penetrometer application: a review” Trans ASAE, 30: 939-944, 1987, 
[12] Ley, G. J., Mullins, C. E., Lal, R., "Effects of soil properties on the strength of weakly structured tropical soils" Soil Till Res., 28, 1-13, 1993

[13] Busscher, W. J., Bauer, P. J., Camp, C. R., Sojka, R. E., "Correction of cone index for soil water content differences in a coastal plain soil” Soil Till Res., 43, 205-217, 1997

[14] Mapfumo, E., Chanasyk, D. S., "Guidelines for safe trafficking and cultivation, and resistancedensity-moisture relations of three disturbed soils from Alberta" Soil Tillage Res, 46, 193-202, 1998

[15] Şeker, C., "The effect of water content on the penetration resistance of different soils, and regression models” Turk J Agric For., 23, 467-471, 1999

[16] Bayat, H., Neyshabouri, M. R., Hajabbasi, M. A., Mahboubi, A. A., Mosaddeghi, M. R, "Comparing neural networks, linear and nonlinear regression techniques to model penetration resistance” Turk J Agric For., 32, 425-433, 2008

[17] Aksakal, E. L., Öztaş, T., "Changes in distribution patterns of soil penetration resistance within a silage-corn field following the use of heavy harvesting equipments” Turk J Agric For., 34, 173179, 2010

[18] Minitab, "Minitab Referenee Manual (Release 7.1)” Minitab Inc. Statc Coll PS 16801, USA, 1991

[19] Craul P. J., "Urban Soils: Applications and Practices” John wiley \& sons, Toronto, 1999

[20] Demiralay, İ., “Toprak Fiziği Ders Notları” Atatürk Üni. Ziraat Fak., Erzurum, 1977

[21] Turgut, B., Öztaş, T., Aksakal, E. L., “ Bazı toprak özelliklerinin penetrasyon direnç değerlerine doğrudan ve dolaylı etkileri” Süleyman Demirel Üniversitesi Ziraat Fakültesi Dergisi, 5 (2), 45-53, 2010

[22] Negiş, H., “ Şeker Pancarı Tarımında Dönemsel Toprak Sıkışmasının Belirlenmesi” Selçuk Üniversitesi, Fen Bilimleri Enstitüsü, Yüksek Lisans Tezi, 72s, Konya, 2014.

[23] Turgut, B., Aksakal, E.L., Öztaş, T., "Toprak sıkışmasına bağlı fiziksel ortam özelliklerindeki etkileşimler” III. Ulusal Karadeniz Ormancıllk Kongresi 20-22 Mayıs 2010, 5, 1439-1446, 2010 